\title{
The effects of PTPN2 loss on cell signalling and clinical outcome in relation to breast cancer subtype
}

\author{
Cynthia Veenstra ${ }^{1}\left(\mathbb{0} \cdot\right.$ Elin Karlsson $^{1} \cdot$ Sanam Mirwani Mirwani $^{1} \cdot$ Bo Nordenskjöld $^{1} \cdot$ Tommy Fornander $^{2}$. \\ Gizeh Pérez-Tenorio ${ }^{1}$ • Olle Stål ${ }^{1}$
}

Received: 19 March 2019 / Accepted: 15 April 2019 / Published online: 25 April 2019

(C) The Author(s) 2019

\begin{abstract}
Purpose The protein tyrosine phosphatase PTPN2 dephosphorylates several tyrosine kinases in cancer-related signalling pathways and is thought to be a tumour suppressor. As PTPN2 is not frequently studied in breast cancer, we aimed to explore the role of PTPN2 and the effects of its loss in breast cancer.

Methods Protein expression and gene copy number of PTPN2 were analysed in a cohort of pre-menopausal breast cancer patients with immunohistochemistry and droplet digital PCR, respectively. PTPN2 was knocked down in three cell lines, representing different breast cancer subtypes, with siRNA transfection. Several proteins related to PTPN2 were analysed with Western blot.

Results Low PTPN2 protein expression was found in 50.2\% of the tumours (110/219), gene copy loss in 15.4\% (33/214). Low protein expression was associated with a higher relapse rate in patients with Luminal A and HER2-positive tumours, but not triple-negative tumours. In vitro studies further suggested a subtype-specific role of PTPN2. Knockdown of PTPN2 had no effect on the triple-negative cell line, whilst knockdown in MCF7 inhibited phosphorylation of Met and promoted that of Akt. Knockdown in SKBR3 led to increased Met phosphorylation and decreased Erk phosphorylation as well as EGF-mediated STAT3 activation.

Conclusion We confirm previous studies showing that the PTPN2 protein is lost in half of the breast cancer cases and gene deletion occurs in 15-18\% of the cases. Furthermore, the results suggest that the role of PTPN2 is subtype-related and should be further investigated to assess how this could affect breast cancer prognosis and treatment response.
\end{abstract}

Keywords PTPN2 $\cdot$ TCPTP $\cdot$ ddPCR $\cdot$ IHC $\cdot$ Breast cancer $\cdot$ Akt $\cdot$ Met $\cdot$ HGF

\section{Introduction}

Phosphorylation of tyrosine kinases is an important mechanism in cellular signalling driving tumourigenesis. Protein tyrosine phosphatases (PTPs) regulate phosphorylation by removing phosphoryl groups and bringing tyrosine kinases

Cynthia Veenstra

cynthia.veenstra.liu@gmail.com

Elin Karlsson

elin.karlsson@regionostergotland.se

Sanam Mirwani Mirwani

mirwani.sanam@gmail.com

Bo Nordenskjöld

bo.nordenskjold@liu.se

Tommy Fornander tommy.fornander@ki.se back to their original state. PTPN2, also known as TCPTP, is an intracellular non-transmembrane phosphatase that is ubiquitously expressed (Cool et al. 1989). There are two main isoforms of PTPN2, namely the $48 \mathrm{kDa}$ variant (TC48) and the $45 \mathrm{kDa}$ variant (TC45) (Cool et al. 1989; ChampionArnaud et al. 1991). A third, less common, isoform is the

Gizeh Pérez-Tenorio

gizeh.perez-tenorio@liu.se

Olle Stål

olle.stal@liu.se

1 Division of Clinical Sciences, Department of Clinical and Experimental Medicine and Department of Oncology, Faculty of Health Sciences, Linköping University, 58185 Linköping, Sweden

2 Department of Oncology-Pathology, Karolinska University Hospital and Karolinska Institute, Stockholm, Sweden 
$41 \mathrm{kDa}$ (TC41) isoform (Bussieres-Marmen et al. 2014). TC48 is localised to the endoplasmic reticulum, whilst TC45 resides in the nucleus with the possibility of translocating to the cytoplasm upon stimuli, like growth factors or cellular stress (Tiganis et al. 1998; Lam et al. 2001). PTPN2 has been proposed as a tumour suppressor, following several deletion and overexpression studies in haematological and solid malignancies (Kleppe et al. 2010; Karlsson et al. 2015; Shields et al. 2013; Hoshida et al. 2008; Lee et al. 2009).

Breast cancer is a heterogeneous disease, subdivided into several subtypes. The least aggressive subtype is known as Luminal A and is characterised as oestrogen receptor (ER) and progesterone receptor (PR)-positive, human epidermal growth factor receptor-2 (HER2)-negative and usually Nottingham grade (NHG) 1 or 2. The Luminal B subtype is further divided into B1 and B2. Luminal B1 is ER-positive, HER2-negative, and NHG 3, whilst Luminal B2 is positive for ER and HER2. Tumours negative for ER and PR, and positive for HER 2 are called HER2-like tumours. Triplenegative breast cancer tumours are distinguished by their lack of the three markers. The three last-mentioned subtypes are mostly NHG $2 / 3$ and the patient outcome is often poor (Goldhirsch et al. 2011).

While PTPN2 is commonly found deleted in non-Hodgkin lymphoma and T-cell acute lymphoblastic leukaemia, few studies exist on the role of PTPN2 in breast cancer (Kleppe et al. 2010, 2011). The PTPN2 protein has been shown to be lost in ER-negative breast cancer, more so in triple-negative breast cancers (TNBC) (Shields et al. 2013) and we have previously found that the protein is expressed at low levels in $53.3 \%$ of the tumours in a cohort of low-risk breast cancer patients (Karlsson et al. 2018). PTPN2 gene copy loss was reported in $16 \%$ and $18 \%$ in a high-risk postmenopausal breast cancer cohort and low risk, respectively. Loss was correlated with poor patient outcome in the highrisk cohort (Karlsson et al. 2015, 2018). Various substrates of PTPN2 play important roles in the genesis and progression of breast cancer amongst others the epidermal growth factor receptor (EGFR), STAT3, and proposedly the Met receptor (Sangwan et al. 2008; Tiganis et al. 1998, 1999; Yamamoto et al. 2002). In this study, the role of PTPN2 was explored in the different subtypes of breast cancer in both a subset of pre-menopausal breast cancer patients and cell lines.

\section{Materials and methods}

\section{Patient material}

Between 1976 and 1990, the Stockholm breast cancer trial recruited a total of 1226 pre- and post-menopausal patients with tumours larger than $30 \mathrm{~mm}$ and/or positive lymph nodes in a randomised trial comparing $46 \mathrm{~Gy}$ of locoregional post-operative radiotherapy with 12 courses of Milan-type CMF adjuvant chemotherapy (Bonadonna et al. 1976). There were 547 pre-menopausal patients included in the trial (Rutqvist and Johansson 2006). Tumour tissues obtained from surgery were formalin-fixed, paraffinembedded (FFPE) and stored at room temperature until usage. Genomic DNA was previously extracted from FFPE tumour tissues using QIAamp DNA FFPE Tissue Kit (Qiagen, Hilden, Germany) (Veenstra et al. 2016). Tumour tissues were available from 219 of the pre-menopausal patients and DNA extracted from the FFPE tissues was available from 214 (Fig. 1). Retrospective studies on this tumour material were approved by the ethical committee at Karolinska Institute in Stockholm, Sweden. The patient and treatment characteristics are displayed in Table 1. ER status was obtained by isoelectric focusing, with a threshold of $0.05 \mathrm{fmol} / \mu \mathrm{g}$ DNA. HER 2 overexpression was established by immunohistochemical analysis, per the Herceptest Guidelines for membrane staining (Dako Agilent, Santa Clara, CA, USA). Phospho-Akt-S473 (pAkt), pMetY1349 (pMet), and HGF have been previously analysed by immunohistochemistry (IHC) (Veenstra et al. 2016).

\section{Tissue microarray}

Tissue microarrays (TMAs) of the available tumour tissues were manufactured as follows: representative tumour tissue blocks were used as donor blocks, sections from these blocks were stained with haematoxylin and eosin after which three biologically representative regions were selected for all tumour samples. Three tissue cores of $0.8 \mathrm{~mm}$ in diameter were taken from these regions and re-embedded in paraffin blocks. The blocks were cut into $5 \mu \mathrm{M}$ sections and placed on frost-coated microscope slides. The sections were covered with a layer of paraffin upon cutting and stored at $4{ }^{\circ} \mathrm{C}$.

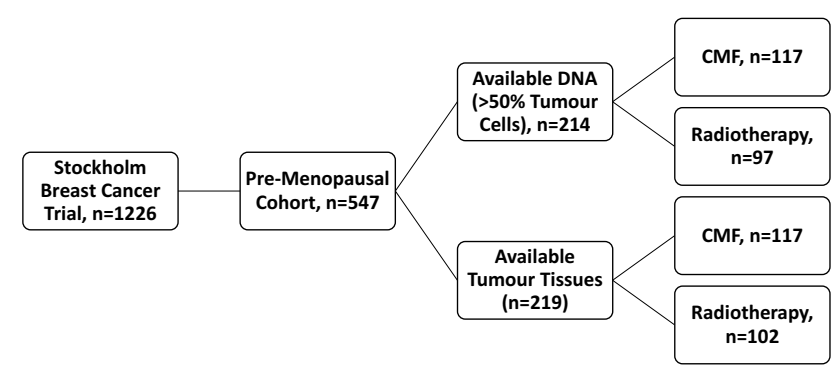

Fig. 1 Patient distribution throughout the pre-menopausal breast cancer patient cohort. Patients were randomised to receive either radiotherapy or chemotherapy. $C M F$ cyclophosphamide, methotrexate, and 5-fluoruocil 
Table 1 Patient characteristics and clinicopathological parameters in association with PTPN2 protein expression and PTPN2 copy loss

\begin{tabular}{|c|c|c|c|c|c|c|c|c|}
\hline & \multirow{2}{*}{$\begin{array}{l}\text { Total (tissue) } \\
n(\%)\end{array}$} & \multicolumn{2}{|c|}{ PTPN2 expression } & \multirow[t]{2}{*}{$p$ value } & \multirow{2}{*}{$\begin{array}{l}\text { Total (DNA) } \\
n(\%)\end{array}$} & \multicolumn{2}{|c|}{ PTPN2 copy loss } & \multirow[t]{2}{*}{$p$ value } \\
\hline & & $\begin{array}{l}\text { Low } \\
n(\%)\end{array}$ & $\begin{array}{l}\text { High } \\
n(\%)\end{array}$ & & & $\begin{array}{l}\text { Deletion } \\
n(\%)\end{array}$ & $\begin{array}{l}\geq 2 \text { copies } \\
n(\%)\end{array}$ & \\
\hline Total & 219 & $110(50.2)$ & $109(49.8)$ & & 214 & $33(15.4)$ & $181(84.6)$ & \\
\hline \multicolumn{9}{|c|}{ Lymph node status } \\
\hline 0 & $28(12.8)$ & $14(50.0)$ & $14(50.0)$ & 0.998 & $27(12.6)$ & $2(7.4)$ & $25(92.6)$ & 0.356 \\
\hline $1-3$ & $121(55.3)$ & $61(50.4)$ & $60(49.6)$ & & $116(54.2)$ & $21(18.1)$ & $95(81.9)$ & \\
\hline$>3$ & $70(32.0)$ & $35(50.0)$ & $35(50.0)$ & & $71(33.2)$ & $10(14.1)$ & $61(85.9)$ & \\
\hline \multicolumn{9}{|c|}{ Tumour size (mm) } \\
\hline$\leq 20$ & $81(37)$ & $40(49.4)$ & $41(50.6)$ & 0.846 & $83(38.8)$ & $11(13.3)$ & $72(86.7)$ & 0.502 \\
\hline$>20$ & $132(60.3)$ & $67(50.8)$ & $65(49.2)$ & & $126(58.9)$ & $21(16.7)$ & $105(83.3)$ & \\
\hline Unavailable & $6(2.7)$ & & & & $5(2.3)$ & & & \\
\hline \multicolumn{9}{|l|}{ NHG } \\
\hline 1 & $47(21.5)$ & $20(42.6)$ & $27(57.4)$ & 0.573 & $50(23.4)$ & $6(12.0)$ & $44(88.0)$ & 0.679 \\
\hline 2 & $112(51.1)$ & $57(50.9)$ & $55(49.1)$ & & $109(50.9)$ & $19(17.4)$ & $90(82.6)$ & \\
\hline 3 & $52(23.7)$ & $27(51.9)$ & $25(48.4)$ & & $46(21.5)$ & $7(15.2)$ & $39(84.8)$ & \\
\hline Unavailable & $8(3.7)$ & & & & $9(4.2)$ & & & \\
\hline \multicolumn{9}{|c|}{ Adjuvant treatment } \\
\hline $\mathrm{CMF}$ & $117(53.4)$ & $54(46.2)$ & $63(53.8)$ & 0.197 & $117(54.7)$ & $15(12.8)$ & $102(87.2)$ & 0.247 \\
\hline RT & $102(46.6)$ & $56(54.9)$ & $46(45.1)$ & & $97(45.3)$ & $18(18.6)$ & $79(81.4)$ & \\
\hline \multicolumn{9}{|l|}{ ER status } \\
\hline Negative* & $59(26.9)$ & $35(59.3)$ & $24(40.7)$ & 0.037 & $55(25.7)$ & $5(9.1)$ & $50(90.9)$ & 0.131 \\
\hline Positive $^{\dagger}$ & $139(63.5)$ & $60(43.2)$ & $79(56.8)$ & & $141(65.9)$ & $25(17.7)$ & $116(82.3)$ & \\
\hline Unavailable & $21(9.6)$ & & & & $18(8.4)$ & & & \\
\hline \multicolumn{9}{|l|}{ HER2 status } \\
\hline Negative & $183(83.6)$ & $92(50.3)$ & $91(49.7)$ & 0.900 & $180(84.1)$ & $28(15.6)$ & $152(84.4)$ & 0.953 \\
\hline Positive & 35 (16) & $18(51.4)$ & 17 (48.6) & & $33(15.4)$ & $5(15.2)$ & $28(84.8)$ & \\
\hline Unavailable & $1(0.4)$ & & & & $1(0.5)$ & & & \\
\hline \multicolumn{9}{|c|}{ pAkt cytoplasm } \\
\hline Negative & $113(51.6)$ & 70 (61.9) & $43(38.1)$ & $<0.001$ & $106(49.5)$ & $21(63.6)$ & $85(49.7)$ & 0.101 \\
\hline Positive & $104(47.5)$ & $38(36.5)$ & $66(63.5)$ & & $98(45.8)$ & $12(36.4)$ & $86(50.3)$ & \\
\hline Unavailable & $2(0.9)$ & & & & $10(4.7)$ & & & \\
\hline \multicolumn{9}{|l|}{ pAkt $N \geq C$} \\
\hline No & $149(68)$ & $64(43.0)$ & $85(57.0)$ & 0.003 & $142(66.4)$ & $20(14.1)$ & $122(85.9)$ & 0.219 \\
\hline Yes & $68(31.1)$ & $44(65.7)$ & $23(34.3)$ & & $62(28.9)$ & $13(21.0)$ & $49(79.0)$ & \\
\hline Unavailable & $2(0.9)$ & & & & $10(4.7)$ & & & \\
\hline \multicolumn{9}{|c|}{ pMet membrane } \\
\hline Negative & $158(72.1)$ & $94(59.5)$ & $64(40.5)$ & $<0.001$ & 147 (68.7) & $22(15.0)$ & $125(85.0)$ & 0.472 \\
\hline Positive & $55(25.1)$ & $16(29.1)$ & $39(70.9)$ & & $52(24.3)$ & $10(19.2)$ & $42(80.8)$ & \\
\hline Unavailable & $6(2.8)$ & & & & $15(7)$ & & & \\
\hline \multicolumn{9}{|c|}{ pMet cytoplasm } \\
\hline Negative & $100(45.7)$ & $75(75.0)$ & $25(25.0)$ & $<0.001$ & $90(42.1)$ & $15(16.7)$ & $75(83.3)$ & 0.838 \\
\hline Positive & $113(51.6)$ & $35(31.0)$ & $78(69.0)$ & & $109(50.9)$ & 17 (15.6) & $92(84.4)$ & \\
\hline Unavailable & $6(2.7)$ & & & & $15(7)$ & & & \\
\hline \multicolumn{9}{|l|}{ HGF stroma } \\
\hline Negative & $102(46.6)$ & $55(53.9)$ & $47(46.1)$ & 0.243 & $98(45.8)$ & $14(14.3)$ & 84 (85.7) & 0.440 \\
\hline Positive & 109 (49.8) & $50(45.9)$ & $59(54.1)$ & & $98(45.8)$ & $18(18.4)$ & 80 (81.6) & \\
\hline Unavailable & $8(3.6)$ & & & & $18(8.4)$ & & & \\
\hline HGF cytoplasn & & & & & & & & \\
\hline
\end{tabular}


Table 1 (continued)

\begin{tabular}{|c|c|c|c|c|c|c|c|c|}
\hline & \multirow{3}{*}{$\begin{array}{l}\text { Total (tissue) } \\
n(\%)\end{array}$} & \multicolumn{2}{|c|}{ PTPN2 expression } & \multirow[t]{3}{*}{$p$ value } & \multirow{3}{*}{$\begin{array}{l}\text { Total (DNA) } \\
n(\%)\end{array}$} & \multicolumn{2}{|c|}{ PTPN2 copy loss } & \multirow[t]{3}{*}{$p$ value } \\
\hline & & Low & High & & & Deletion & $\geq 2$ copies & \\
\hline & & $n(\%)$ & $n(\%)$ & & & $n(\%)$ & $n(\%)$ & \\
\hline Negative & $108(49.3)$ & $65(60.2)$ & $43(39.8)$ & 0.003 & $104(48.6)$ & $17(16.3)$ & $87(83.7)$ & 0.967 \\
\hline Positive & $104(47.4)$ & $41(39.4)$ & $63(60.6)$ & & $93(43.5)$ & $15(16.1)$ & $78(83.9)$ & \\
\hline Unavailable & $5(2.3)$ & & & & $17(7.9)$ & & & \\
\hline \multicolumn{9}{|c|}{ Breast cancer subtype } \\
\hline Luminal A & $107(48.0)$ & $49(45.8)$ & $58(54.2)$ & 0.412 & $109(50.9)$ & $18(16.5)$ & $91(83.5)$ & 0.337 \\
\hline Luminal B1 & $13(5.9)$ & $4(30.8)$ & $9(69.2)$ & 0.152 & $14(6.5)$ & $3(21.4)$ & $11(78.6)$ & 0.483 \\
\hline Luminal B2 & $14(6.4)$ & $5(35.7)$ & $9(64.3)$ & 0.261 & $14(6.5)$ & $3(21.4)$ & $11(78.6)$ & 0.549 \\
\hline HER2 & $16(7.3)$ & $10(62.5)$ & $6(37.5)$ & 0.299 & $14(6.5)$ & $2(14.3)$ & $12(85.7)$ & 0.612 \\
\hline TNBC & 43 (19.6) & $25(58.1)$ & $18(41.9)$ & 0.145 & $40(18.7)$ & $3(7.5)$ & $37(92.5)$ & 0.137 \\
\hline Unavailable & $26(12.8)$ & & & & $23(10.7)$ & & & \\
\hline
\end{tabular}

$E R$ oestrogen receptor, $N H G$ Nottingham Grade, $N \geq C$ nuclear expression equal to or bigger than cytoplasmic expression, $T N B C$ triple-negative breast cancer

$p$ values printed in bold are considered significant

$*<0.05 \mathrm{fmol} / \mu \mathrm{g} \mathrm{DNA},{ }^{\dagger} \geq 0.05 \mathrm{fmol} / \mu \mathrm{g}$ DNA

\section{Immunohistochemistry}

TMA sections were cleared from the paraffin layer by upright incubation at $60{ }^{\circ} \mathrm{C}$. Sections were further deparaffinised, rehydrated, and antigen-retrieved using the DAKO PT Module (PT Link, Dako Agilent) with DAKO PT Low pH Buffer (Envision FLEX target retrieval solution low, Dako Agilent). The sections were incubated for 10 min with serum-free protein block to reduce unspecific binding (Spring Bioscience, Fremont, CA, USA). The sections were incubated overnight at $4{ }^{\circ} \mathrm{C}$ with a PTPN2 antibody recognising both main isoforms (Proteintech, Rosemont, IL, USA; 11214-1-AP, diluted 1:40) prior to 30 min' incubation at room temperature with an antirabbit secondary antibody (EnVision ${ }^{\mathrm{TM}}$, Dako Agilent). The arrays were then coloured with 3'-diaminobenzidine tetrahydrochloride $\left(\mathrm{DAB} / \mathrm{H}_{2} \mathrm{O}_{2}\right)$ solution and counterstained with Mayer's haematoxylin (Fluka Analytical, Sigma-Aldrich, St. Louis, MO, USA). Dehydration was established using a series of ethanol dilutions. Wholeslide images were obtained with Aperio ScanScope AT (Leica Microsystems, Wetzler, Germany). Grading was performed by three independent investigators (CV, EK, and SMM) and cytoplasmic staining of tumour cells was graded as negative, weak, intermediate, or strong. PTPN2 protein staining could be successfully evaluated in 219 tumours. For analyses, groups were dichotomised into low (negative-to-weak) and high (intermediate-to-strong). Protein specificity of the PTPN2 antibody was previously validated in our lab (Karlsson et al. 2018).

\section{Droplet digital PCR}

PTPN2 copy number variations (CNV) were measured with droplet digital PCR (ddPCR). Primers and probe against PTPN2 exon 10 (accession number: NM_080422.2) were designed using Primer Expression v1.5a (Applied Biosystems, Carlsbad, CA, USA). Sequences were as follows: forward primer: 5'-AAGCCCACTCCGGAAACTAAA-3', reversed primer: 5'-AAACAAACAACTGTGAGGCAATCT A-3', probe: 5'-TGAGGCTCGCTAACC-3'. The resulting product had a total amplicon length of $65 \mathrm{nt}$. The annealing temperature was $64.2^{\circ} \mathrm{C}$. AP3B1 (dHsaCP2500348; Bio$\mathrm{Rad}$, Hercules, CA, USA) was chosen as the reference gene as previously described, as well as the followed protocol (Veenstra et al. 2016). CNV of PTPN2 could be successfully assessed in 214 tumours.

\section{Cell lines and growth factor treatment}

The breast cancer cell lines MCF7, MDA-MB-468, and SKBR3 cells were purchased from the American Type Culture Collection (ATCC, Manassas, VA, USA), the authenticity of the cell lines was validated prior purchase, using short-tandem repeat (STR) profiling. MCF7, representing Luminal A disease, and MDA-MB-468, representing TNBC, were cultured in DMEM high glucose media supplemented with $10 \%$ foetal bovine serum and $0.5 \%$ L-glutamine (complete medium) (Gibco, Invitrogen, Carlsbad, CA, USA). SKBR3, representing HER2-like breast cancer, was cultured in DMEM media supplemented with $10 \%$ foetal bovine 
serum and $0.5 \%$ L-glutamine (complete medium) (Gibco). Experiments were performed between passage 5 AND 30. The cells were starved $24 \mathrm{~h}$ prior to growth factor treatment in medium containing 0.5\% FBS (low-serum medium). Cells were treated with $30 \mathrm{ng} / \mathrm{mL}$ human EGF with carrier [Cell Signaling Technology (CST), Beverly, MA, USA] and/or $50 \mathrm{ng} / \mathrm{mL}$ recombinant human HGF diluted in PBS containing $0.5 \%$ BSA (CST).

\section{siRNA transfection}

Cells were seeded in six-well culture plates in complete medium at $2 \times 10^{5}$ cells $/ \mathrm{mL}$ shortly before transfection and incubated under standard conditions until transfection. The cells were transfected with $10 \mathrm{nM}$ scrambled siRNA (AllStars Negative Control siRNA, Qiagen) or $10 \mathrm{nM}$ siRNA targeted against both main isoforms of PTPN2 (siRNA_15 Qiagen) using HiPerFect reagent (Qiagen), following the manufacturer's fast forward protocol. After $48 \mathrm{~h}$, cells were used for follow-up experiments. A positive control siRNA (AllStars Hs Cell Death Control, Qiagen), knocking down ubiquitous human cell survival genes, was included in every experiment. All positive controls performed resulted in $>90 \%$ cell death as visualised by light microscopy. Unspecific effects of transfection reagents were discarded by mocktransfecting the cells during the optimisation of the experiments. Knockdown control was performed using Western blot and gene expression analysis (at least $80 \%$ knockdown per experiment; results not shown).

\section{Western blot analysis}

The cells were harvested in RIPA lysis buffer containing protease inhibitor cocktail (cOmplete, Roche, Basil, Switzerland) and phosphatase inhibitor (PhosSTOP, Roche), lysates were snap-frozen and stored at $-70{ }^{\circ} \mathrm{C}$ until usage. Twenty-five $\mu \mathrm{g}$ protein samples were loaded on a pre-cast Mini Protean TGX 4-15\% gradient gels (Bio-Rad) and separated by electrophoresis. The proteins were then transferred to a membrane using the Trans-Blot Turbo Transfer System (Bio-Rad). The membranes were blocked for $1 \mathrm{~h}$ at room temperature in blocking buffer (TBST with 5\% milk powder or BSA). The membranes were incubated overnight at $4{ }^{\circ} \mathrm{C}$ with primary antibodies, after thorough washing, the membranes were incubated for $1 \mathrm{~h}$ at room temperature with appropriate HRP-conjugated secondary antibodies (Dako Agilent). Primary antibodies used: phospho-Met Y1349 (pMet, 1:1000, Abcam, Cambridge, UK), pEGFR Y1068 (pEGFR, 1:1000, CST), pAkt S473 (pAkt, 1:1000, CST), pErk 1/2 Thr202/Y204 (pErk, 1:1000, CST), p-STAT3 Y705 (pSTAT3, 1:1000, CST), PTPN2 TC45 (1:1000, CST), and GAPDH-HRP conjugated (1:5000, Abcam).

\section{Statistical analyses}

Relationships between factors were assessed using Pearson's Chi squared test. Survival of patients in different groups was calculated using Kaplan-Meier and the Mantel-Cox test estimated the statistical differences. Hazard ratio (HR) was calculated with Cox proportional hazards regression and reported with $95 \%$ confidence intervals (CI). Distant recurrence-free survival (DRFS) was defined as the period of time passed between the diagnosis of the primary tumour and the distant recurrence. Loco-regional recurrence-free survival was defined likewise but for local-regional recurrence. A multivariate Cox model was carried out to assess the interaction between benefit from radiotherapy versus chemotherapy (CMF) and PTPN2 protein expression. As described previously, in this cohort of patients the subtypes were defined by ER-status, HER2-status, and NHG; Ki67 staining was not available (Veenstra et al. 2016). For survival analysis, overexpression of HER2, rather than the HER2-like subtype, was used, as there were few patients in the HER2-like subtype group. Statistical analyses were performed with IBM SPSS for Windows, Version 23 (IBM Corp, Armonk, NY, USA). The criterion for statistical significance was $p \leq 0.05$.

\section{Results}

\section{PTPN2 copy number variations and protein expression}

To determine the expression levels of PTPN2, IHC was carried out with an antibody recognising both main isoforms of PTPN2 (TC45 and TC48). Expression was primarily localised to the cytoplasm and high expression (intermediate to strong staining) was found in $49.8 \%$ (109/219) of the tumours, low expression in 50.2\% (110/219) of the cases (Table 1). CNV was analysed by ddPCR in DNA extracted from the tumours. PTPN2 copy loss was detected in $15.4 \%$ (33/214) and two or more copies were found in $84.6 \%$ (181/214) (Table 1). Copy numbers and protein expression did not correlate with each other $(p=0.7)$.

\section{PTPN2 in relation to clinicopathological characteristics}

Whilst PTPN2 copy loss did not correlate to any of the clinicopathological parameters, low PTPN2 protein expression was found to be correlated with ER-negative tumours and pAkt status in the cytoplasm. When pAkt expression was mainly localised to the nucleus (pAkt $\mathrm{N} \geq \mathrm{C}$ ), it correlated with low PTPN2 expression.

The proposed PTPN2 substrate Met was found to be associated with PTPN2, membranous and cytoplasmic 
phosphorylated Met were more often positive in PTPN2positive tumours, which was specifically apparent in the Luminal A subtype (cytoplasmic pMet: $p<0.005$ and membranous pMet: $p=0.038$ ). Cytoplasmic HGF, Met's ligand, correlated with PTPN2 expression. None of the breast cancer subtypes showed a direct correlation with PTPN2 staining or copy loss. All associations are listed in Table 1.

\section{PTPN2 is correlated with poor outcome}

Low PTPN2 protein expression was associated with a higher risk for distant recurrence (Fig. 2a), this was even more apparent in the Luminal A subtype and tumours

\section{A}
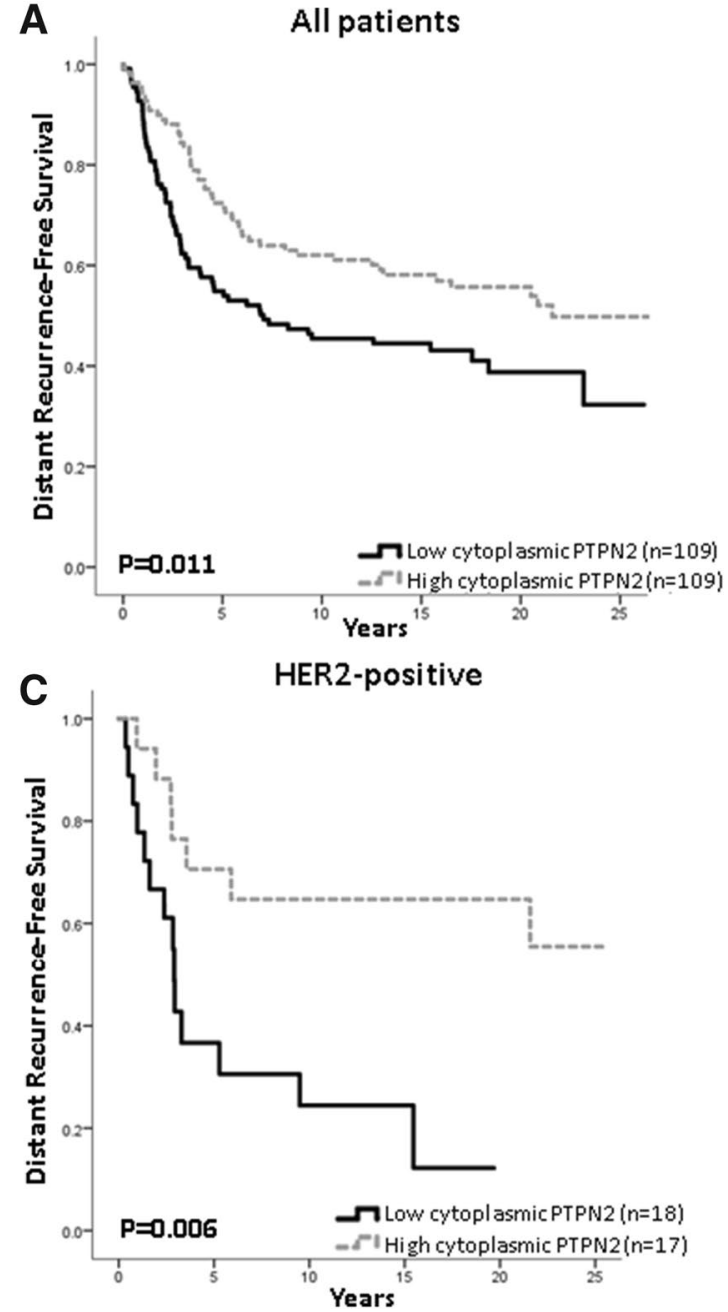

Fig. 2 Distant recurrence-free survival analyses of patients with tumours showing low or high PTPN2 protein expression, in a all patients (high vs low $\mathrm{HR}=0.62 ; 95 \%$ CI $0.43-0.90, p=0.012$ ), b patients with Luminal A disease $(\mathrm{HR}=0.53$; 95\% CI $0.30-0.91$, with HER2 overexpression, but not in the triple-negative subtype (Fig. 2b-d). PTPN2 gene copy number did not have prognostic value in relation to all patients or subtypes (copy loss vs $\geq 2$ copies, all patients: $\mathrm{HR}=1.15$; 95\% CI 0.70-1.88, $p=0.58$; Luminal A: HR $=1.44 ; 95 \%$ CI $0.75-2.8, p=0.28$; HER2 positive: $\mathrm{HR}=0.19 ; 95 \%$ CI $0.03-1.39, p=0.1$; TNBC: HR $=0.53 ; 0.07-3.97$, $p=0.538)$. Protein loss was found to be related to worse survival in patients with tumours with NHG 2, with a similar trend for NHG 1, whilst PTPN2 copy loss was associated with worse survival in patients with tumours with NHG 1, neither was associated with DRFS at a high grade (Fig. 3a-f).
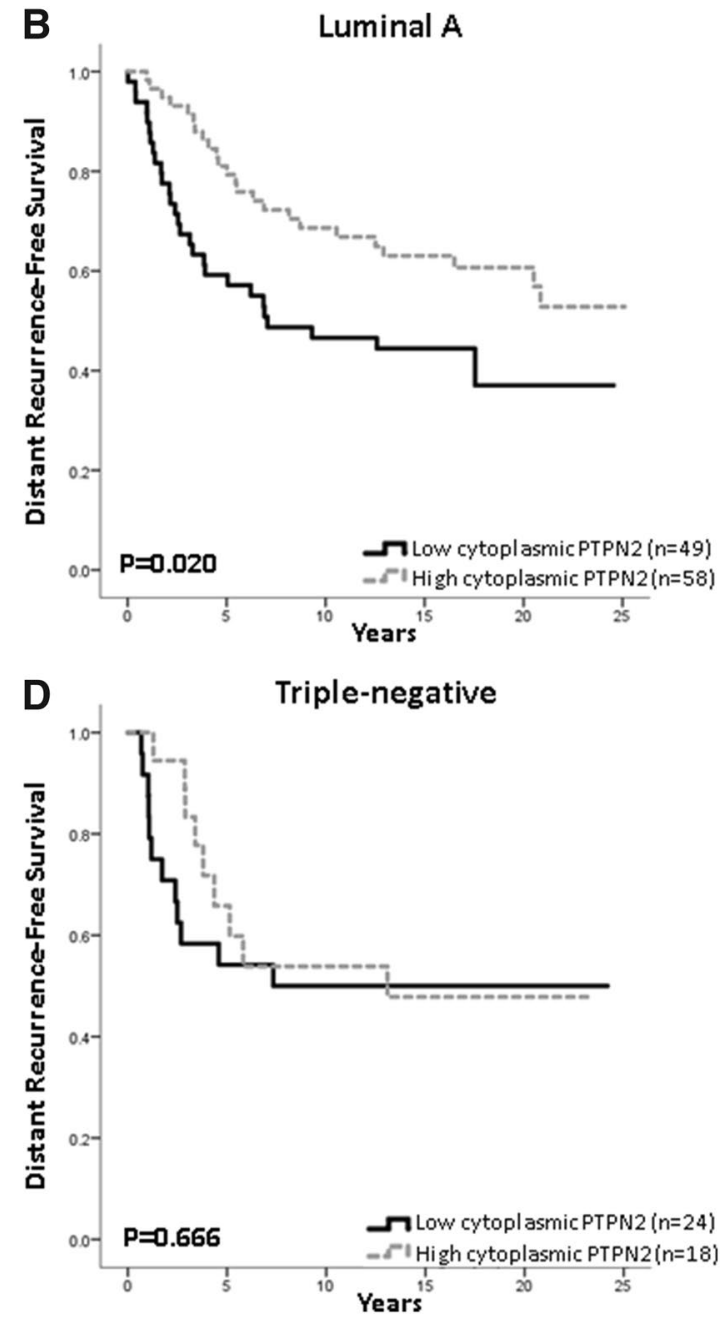

$p=0.022)$, c patients with HER2 overexpressing tumours $(\mathrm{HR}=0.28$; $95 \%$ CI $0.11-0.74, p=0.010$ ), and $\mathbf{d}$ patients with triple-negative disease $(\mathrm{HR}=0.83 ; 95 \% \mathrm{CI} 0.35-1.97 ; p=0.67)$ 
Patients with tumours harbouring both low PTPN2 expression and low membranous pMet expression had a worse DRFS compared with patients with high PTPN2 expression and low pMet (Fig. 4a). For patients with tumours carrying high membranous pMet expression, there was no difference in survival in relation to PTPN2 protein expression (Fig. 4b). In the case of low membranous pMet, similar results were seen when selecting patients for Luminal A disease (HR $=0.491 ; 95 \%$ CI $0.258-0.935$, $p=0.030)$ and HER2 overexpression $(\mathrm{HR}=0.201 ; 95 \% \mathrm{CI}$ $0.044-0.922, p=0.039)$, but not for TNBC $(\mathrm{HR}=0.541$; $95 \%$ CI $0.190-1.541, p=0.25$ ).

\section{Prediction of radiotherapy benefit}

Radiotherapy is known to markedly reduce loco-regional recurrence risk and this was significant for patients with tumours expressing high cytoplasmic PTPN2 levels, but for patients with low cytoplasmic PTPN2 disease there was no significant difference in local recurrence rate between the radiotherapy and CMF groups (Fig. 5a, b). For patients with low, respectively, high cytoplasmic PTPN2 disease, distant recurrence-free survival was not significantly different between patients in the two treatment arms (Fig. 5c, d).

\section{PTPN2 knockdown responses are subtype-dependent}

To evaluate if the role of PTPN2 is subtype-dependent, the protein was knocked down in three different cell lines, representing three different subtypes. Three breast cancer cell lines were transfected for $48 \mathrm{~h}$ with siRNA targeting PTPN2 or with scrambled siRNA. After 24-h starvation, cells were treated with EGF and/or HGF to stimulate pathway signalling. The immunoblots show that PTPN2 knockdown had different effects on the Luminal A representing cell line MCF7, the HER2-positive cell line SKBR3, and the TNBC cell line MDA-MB-468. PTPN2 depletion in MCF7 inhibited both Met constitutive phosphorylation and HGF-mediated phosphorylation and promoted Akt phosphorylation, both constitutive and HGF-mediated. However, pErk, a key protein in the Ras/MAPK pathway, was not affected by PTPN2 knockdown. pSTAT3 and pEGFR were not detected in MCF7 (Fig. 6a). In contrast, SKBR3 cells revealed increased Met phosphorylation levels upon PTPN2 knockdown. Here, PTPN2 loss did not affect Akt phosphorylation, though it did negatively affect pErk, both basic expression and EGF-mediated, and EGF-mediated
STAT3 phosphorylation (Fig. 6b). PTPN2 loss did not affect phosphorylation of any of the tested proteins in the TNBC cell line MDA-MB-468 (Fig. 6c).

\section{Discussion}

PTPN2 has been proposed to have a suppressive role in cancer. In this study, it was aimed to explore the role of PTPN2 loss in breast cancer. Low protein expression was found in $50.2 \%(110 / 219)$ of the tumours. Staining was found to be primarily cytoplasmic, nuclear staining was rarely detected. This is in line with previous findings in our lab, where $53.3 \%$ (354/664) low primarily cytoplasmic PTPN2 expression was found in a large cohort consisting of women with low-risk post-menopausal breast cancer (Karlsson et al. 2018). Gene copy number variation was analysed by ddPCR and it was found that the PTPN2 gene is lost in 15.4\% (33/214) of the cases. Few studies have been conducted on PTPN2 gene copy number in cancer, we have previously reported similar numbers; $15.8 \%$ (34/215) copy loss in tumours from the post-menopausal patients of the Stockholm breast cancer trial (Karlsson et al. 2015) and $17.8 \%(26 / 146)$ in the aforementioned low-risk cohort (Karlsson et al. 2018).

We have previously shown that PTPN2 can predict tamoxifen therapy benefit in post-menopausal breast cancer patients (Karlsson et al. 2015, 2018). Here, we found involvement of PTPN2 in radiotherapy response. While it is widely known that radiotherapy significantly reduces the risk for loco-regional recurrence, this was not found significant for patients with low PTPN2 protein expression; it was true for patients with high PTPN2 expression. PTPN2 low protein expression and copy loss were related to a higher risk of distant recurrence in NHG grade 1 or 2 tumours. This has earlier been shown in a previous study where protein loss was associated with worse survival in NHG 1 tumours (Karlsson et al. 2018), indicating that PTPN2 is not prognostic in high-grade tumours, merely in low-grade tumours. Moreover, low PTPN2 protein expression was related to a higher relapse rate. This has previously been demonstrated with post-menopausal patients in this trial (Karlsson et al. 2015). While in the present study no direct association was found between PTPN2 and subtypes, PTPN2 low protein expression was correlated with a negative ER status, which is per definition non-Luminal and related to more aggressive disease compared with ER-positive tumours. As demonstrated by survival analysis in different subtypes in relation to protein expression, the prognostic value of PTPN2 seemed subtype-related. 

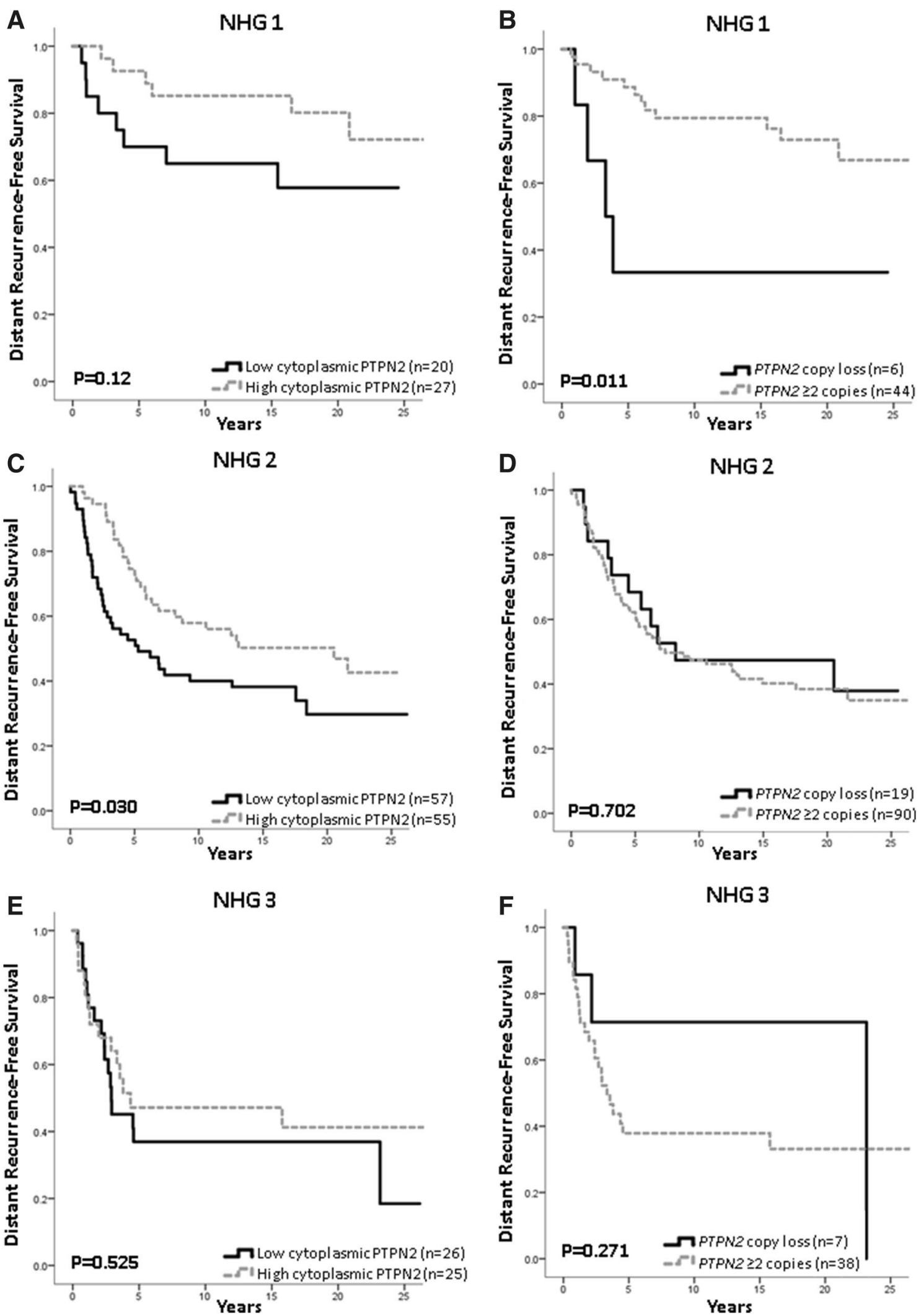
4Fig. 3 Survival analyses in relation to protein or copy loss and NHG status. Survival in patients with tumours with a protein loss with NHG 1 tumours, (high vs low) $\mathrm{HR}=0.46$; 95\% CI $0.15-1.25$, $p=0.12$; b PTPN2 gene copy loss with NHG 1 tumours, (copy loss vs $\geq 2$ copies) $\mathrm{HR}=3.93$; 95\% CI $1.25-12.3, p=0.019$; c protein loss with NHG 2 tumours, HR=0.59; 95\% CI 0.36-0.96, $p=0.032$; d gene copy loss in NHG 2 tumours, $\mathrm{HR}=0.88$; 95\% CI $0.46-1.68$, $p=0.70$; e protein loss in NHG 3 tumours, HR $=0.79$; 95\% CI 0.39 $1.62, p=0.53$; $\mathbf{f}$ copy loss with NHG 3 tumours, $\mathrm{HR}=0.51 ; 95 \% \mathrm{CI}$ $0.13-1.72, p=0.28$

Although PTPN2 protein was commonly lost in TNBC, this was not significantly more compared with other subtypes, unlike shown in a previous report by Shields et al. (2013) showing $67 \%$ protein loss in TNBC tumours. However, it should be noted that their study had considerably fewer patients. The survival analysis in TNBC patients in relation to PTPN2 protein expression showed that loss of protein was not correlated with survival. In vitro studies showing that knockdown of PTPN2 did not alter phosphorylation levels of the tested proteins further indicated the lack of a significance of PTPN2 in triple-negative disease.

PTPN2 protein loss was correlated with less pAkt in the cytoplasm and more in the nucleus. We have previously demonstrated a relation between PTPN2 and Akt in breast cancer, in low-risk breast cancer patients, PTPN2 protein loss was likewise associated with less pAkt in the cytoplasm and more in the nucleus (Karlsson et al. 2018). In our previous study with post-menopausal breast cancer patients, copy loss and low mRNA levels were related to strong pAkt levels, most evident in Luminal A tumours (Karlsson et al.
2015). The relation between the Luminal A subtype, PTPN2, and pAkt was also seen in the Luminal A representing cell line MCF7, where knockdown of PTPN2 lead to increased Akt phosphorylation, but not in the other cell lines. The relation between PTPN2 and Akt has been demonstrated in other cancer types as well, like skin cancer and lung cancer (Lee et al. 2017; Omerovic et al. 2010). The nature of this relationship and the mechanism behind it remain unknown. However, as Akt is not a substrate of PTPN2, the association must be indirect; many substrates of PTPN2 are tyrosine kinases that can activate Akt.

Met has been previously found to be related to PTPN2 and suggested to be a substrate (Sangwan et al. 2008). Here, low PTPN2 protein expression was related to low expression of phosphorylated Met in the cytoplasm and membrane. Patients with low membranous pMet in their tumours and low PTPN2 expression had a poor survival rate, which was also seen in Luminal A disease and patients with tumours overexpressing HER2. In the ER-negative and HER2-positive cell line SKBR3, it was shown that Met phosphorylation increased after knockdown of PTPN2, further suggesting Met to be a substrate of PTPN2. Met phosphorylation has previously been shown to increase upon PTPN2 depletion and HGF stimulation in the ER-negative cell line HeLa (Sangwan et al. 2008). However, Met expression was found to be decreased upon PTPN2 knockdown in the Luminal A cell line MCF7. This suggests that the increase in Akt phosphorylation in PTPN2-depleted cells is not due to Met, but another mechanism. In HeLa cells, PTPN2-deficiency did not alter pAkt or pErk, however, knockdown was followed
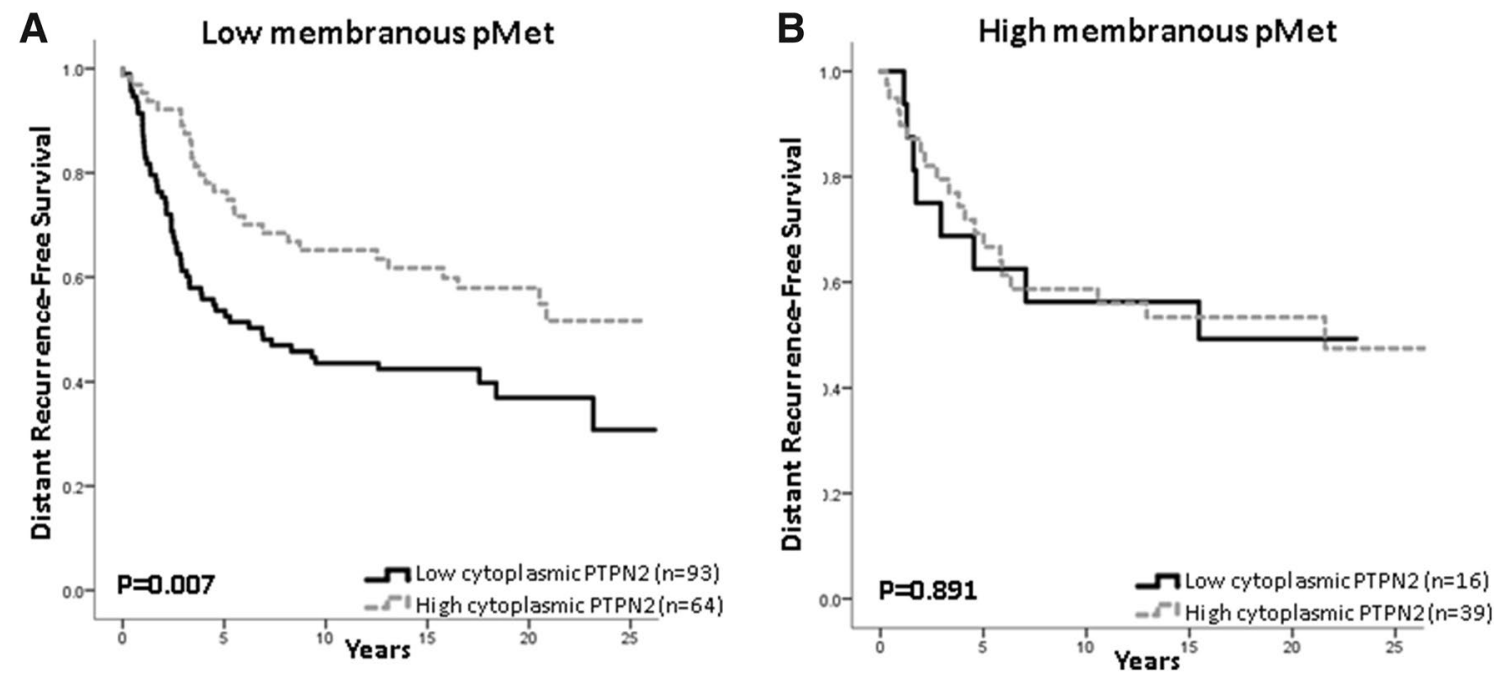

Fig. 4 Distant recurrence-free survival in relation to PTPN2 protein expression and either low membranous pMet expression, a HR=0.537; 95\% CI $0.340-0.847, p=0.008$, or high-membranous pMet expression, b HR =0.944; 95\% CI 0.413-2.16, $p=0.891$ 


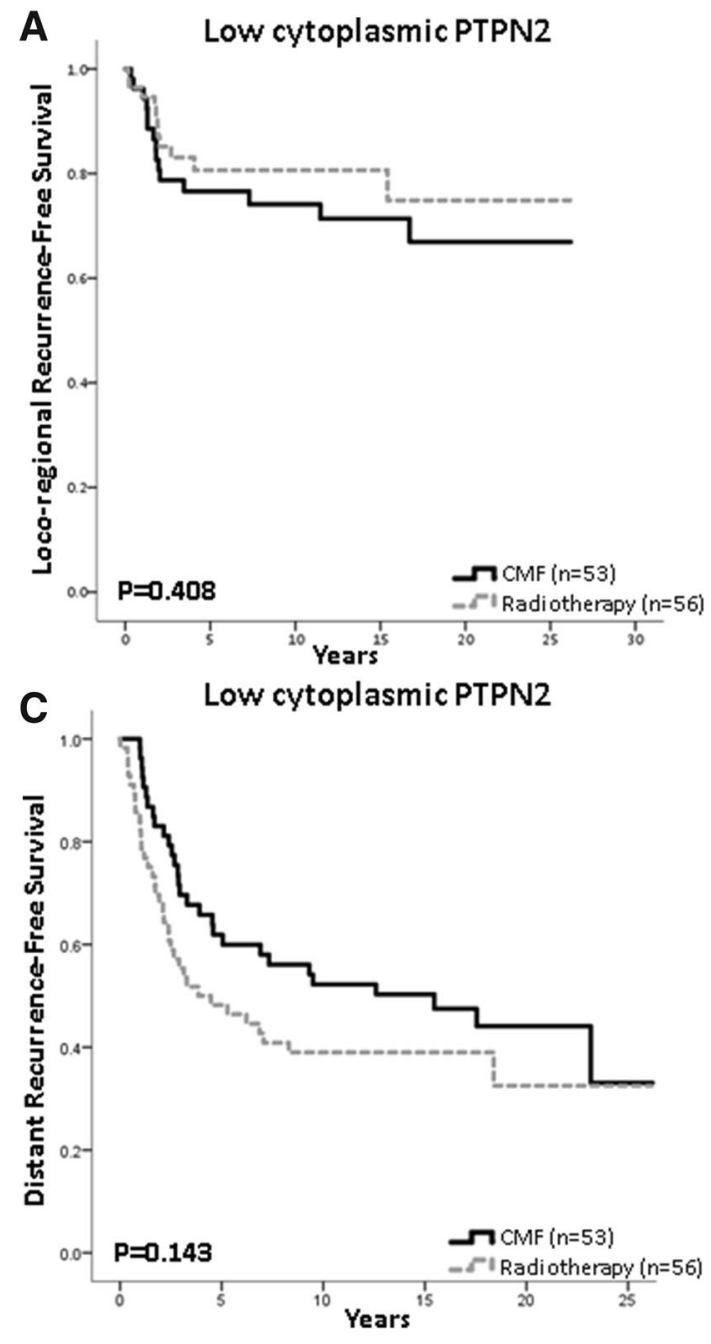

Fig. 5 Estimated survival for patients treated with radiotherapy compared with chemotherapy in relation to PTPN2 protein expression. Loco-regional recurrence-free survival is shown for patients with tumours with a low PTPN2 expression $(\mathrm{HR}=0.721 ; 95 \%$ CI 0.330 $1.572, p=0.410)$ and $\mathbf{b}$ high protein expression $(\mathrm{HR}=0.301 ; 95 \% \mathrm{CI}$

by increased STAT3 phosphorylation after EGF stimulation (Shields et al. 2013). PTPN2 has been previously shown to negatively regulate STAT3 (ten Hoeve et al. 2002). Counterintuitively, here, phosphorylation of STAT3 decreased upon PTPN2 knockdown in SKBR3 cells, though Akt and Erk phosphorylation levels remained unaltered.

In summary, the results presented here confirm previous studies demonstrating low PTPN2 protein expression in half of the breast cancer cases and copy loss in $15-18 \%$ of the cases. Furthermore, this study generated the hypothesis that the prognostic value of PTPN2 might be subtype-related.
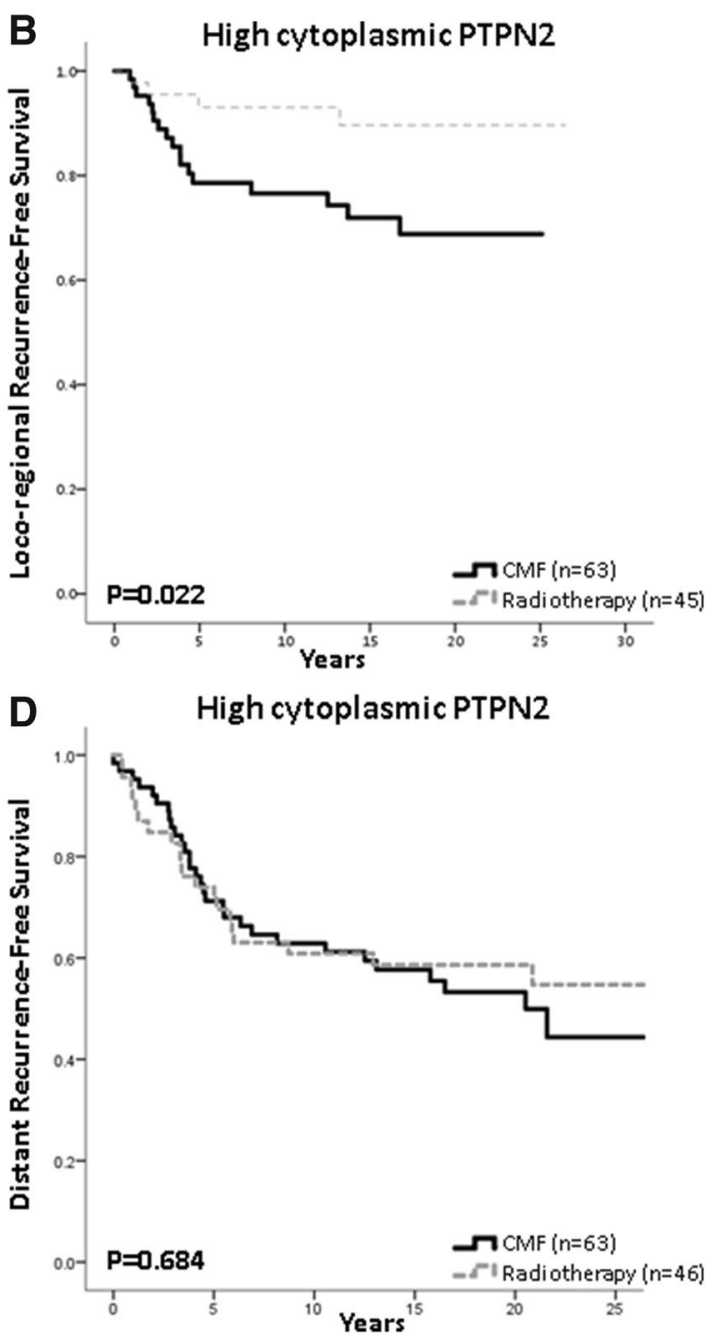

0.101-0.896, $p=0.031$ ), test for interaction: $p=0.20$. Distant recurrence-free survival is shown for patients with tumours harbouring $\mathbf{c}$ low PTPN2 expression $(\mathrm{HR}=1.44 ; 95 \%$ CI $0.881-2.63, p=0.145)$ and d high protein expression $(\mathrm{HR}=0.889 ; 95 \%$ CI $0.504-1.568$, $p=0.685$ ), test for interaction: $p=0.701$

While PTPN2 does not seem to play a prognostic role in TNBC, loss of the protein is associated with worse patient outcome in Luminal A and HER2+ disease. The role of PTPN2 appears different in these two subtypes. In MCF7, representing Luminal A disease, loss of PTPN2 results in Akt phosphorylation independent of Met, whilst in SKBR3, representing HER2+ disease, Akt remains unaffected by PTPN2 depletion and Met is activated instead. To test this hypothesis and assess the implications on breast cancer treatment, more functional studies are needed in multiple breast cancer cell lines. 
Fig. 6 Effect of PTPN2 knockdown and EGF/HGF stimulation on expression of proteins related to PTPN2. Cells were transfected with $10 \mathrm{nM}$ scrambled siRNA or PTPN2 siRNA for $48 \mathrm{~h}$ and serum-starved $24 \mathrm{~h}$ upon 30-min $30 \mathrm{ng} / \mathrm{mL}$ EGF and/or $50 \mathrm{ng} / \mathrm{mL}$ HGF treatment. The panels show representative images of Western blots; the experiments were repeated three times. GAPDH was used as loading control. Empty rows demonstrate that no protein was detected with the antibody. a MCF7 cell lysate, b SKBR3 cell lysate, $\mathbf{c}$ MDAMB-468 cell lysate
A

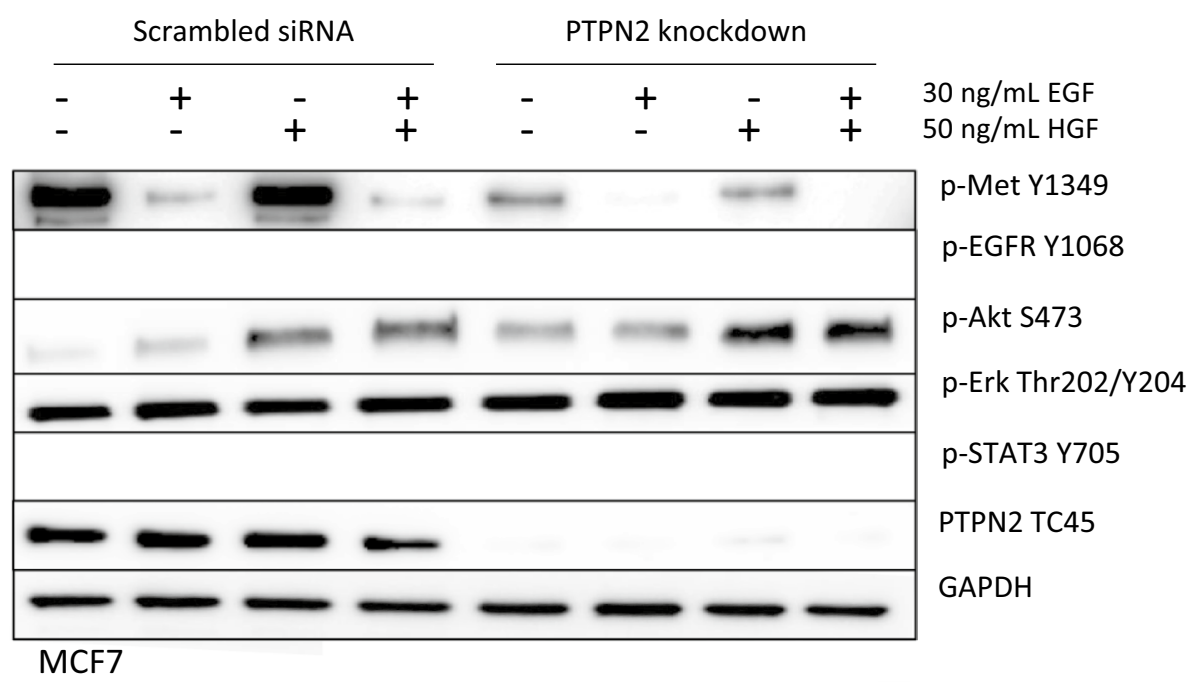

B

\begin{tabular}{|c|c|c|c|c|c|c|c|c|}
\hline \multicolumn{4}{|c|}{ Scrambled siRNA } & \multicolumn{4}{|c|}{ PTPN2 knockdown } & \multirow[b]{2}{*}{$30 \mathrm{ng} / \mathrm{mL}$ EGF } \\
\hline- & + & - & + & - & + & - & + & \\
\hline \multirow[t]{3}{*}{ - } & - & + & + & - & - & + & + & $50 \mathrm{ng} / \mathrm{mL} \mathrm{HGF}$ \\
\hline & & & & - & $\longrightarrow$ & $\longrightarrow$ & - & p-Met Y1349 \\
\hline & & & & & & & & p-EGFR Y1068 \\
\hline & & & & & & $=$ & 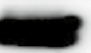 & p-Akt S473 \\
\hline & & & & 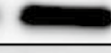 & C & 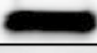 & 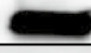 & p-Erk Thr202/Y204 \\
\hline- & 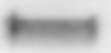 & $=$ & $=$ & $=$ & $\longrightarrow$ & - & $=$ & p-STAT3 Y705 \\
\hline$=$ & $\infty$ & 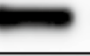 & $m$ & 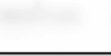 & 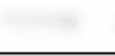 & & 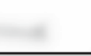 & PTPN2 TC45 \\
\hline & & & & & & & & \\
\hline
\end{tabular}

C

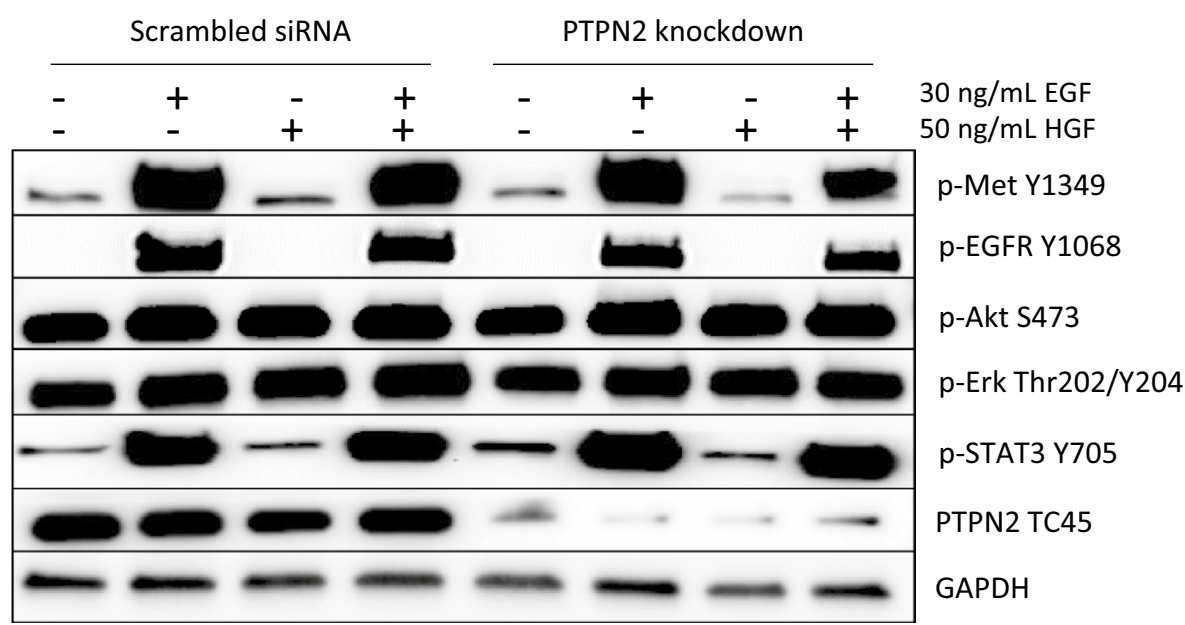

MDA-MB-468 
Acknowledgements The authors want to thank Birgitta Holmlund for constructing the tissue microarrays, Najme Wall for classifying the tumours according to the Nottingham grading system, and Anton Risto for HER 2 analysis. This study was supported by Grants from the Swedish Cancer Society (OS), ALF Grants, Region Östergötland (OS), the LiU Cancer Foundation (OS), the Cancer Research Foundations of Radiumhemmet (TF), and Onkologiska Klinikernas i Linköping Forskningsfond (CV).

\section{Compliance with ethical standards}

Conflict of interest The authors declare that they have no conflict of interest.

Ethical standards The local ethics board at the Karolinska Institute, Stockholm, Sweden, gave ethical approval of retrospective studies.

Open Access This article is distributed under the terms of the Creative Commons Attribution 4.0 International License (http://creativeco mmons.org/licenses/by/4.0/), which permits unrestricted use, distribution, and reproduction in any medium, provided you give appropriate credit to the original author(s) and the source, provide a link to the Creative Commons license, and indicate if changes were made.

\section{References}

Bonadonna G, Brusamolino E, Valagussa P, Rossi A, Brugnatelli L, Brambilla C, De Lena M, Tancini G, Bajetta E, Musumeci R, Veronesi U (1976) Combination chemotherapy as an adjuvant treatment in operable breast cancer. N Engl J Med 294:405-410

Bussieres-Marmen S, Hutchins AP, Schirbel A, Rebert N, Tiganis T, Fiocchi C, Miranda-Saavedra D, Tremblay ML (2014) Characterization of PTPN2 and its use as a biomarker. Methods 65:239-246

Champion-Arnaud P, Gesnel MC, Foulkes N, Ronsin C, Sassone-Corsi P, Breathnach R (1991) Activation of transcription via AP-1 or CREB regulatory sites is blocked by protein tyrosine phosphatases. Oncogene 6:1203-1209

Cool DE, Tonks NK, Charbonneau H, Walsh KA, Fischer EH, Krebs EG (1989) cDNA isolated from a human T-cell library encodes a member of the protein-tyrosine-phosphatase family. Proc Natl Acad Sci USA 86:5257-5261

Goldhirsch A, Wood WC, Coates AS, Gelber RD, Thurlimann B, Senn HJ, Panel M (2011) Strategies for subtypes-dealing with the diversity of breast cancer: highlights of the St. Gallen International Expert Consensus on the Primary Therapy of Early Breast Cancer 2011. Ann Oncol 22:1736-1747

Hoshida Y, Villanueva A, Kobayashi M, Peix J, Chiang DY, Camargo A, Gupta S, Moore J, Wrobel MJ, Lerner J, Reich M, Chan JA, Glickman JN, Ikeda K, Hashimoto M, Watanabe G, Daidone MG, Roayaie S, Schwartz M, Thung S, Salvesen HB, Gabriel S, Mazzaferro V, Bruix J, Friedman SL, Kumada H, Llovet JM, Golub TR (2008) Gene expression in fixed tissues and outcome in hepatocellular carcinoma. N Engl J Med 359:1995-2004

Karlsson E, Veenstra C, Emin S, Dutta C, Perez-Tenorio G, Nordenskjold B, Fornander T, Stal O (2015) Loss of protein tyrosine phosphatase, non-receptor type 2 is associated with activation of AKT and tamoxifen resistance in breast cancer. Breast Cancer Res Treat 153:31-40

Karlsson E, Veenstra C, Garsjo J, Nordenskjold B, Fornander T, Stal O (2018) PTPN2 deficiency along with activation of nuclear Akt predict endocrine resistance in breast cancer. J Cancer Res Clin Oncol 145:599
Kleppe M, Lahortiga I, El Chaar T, De Keersmaecker K, Mentens N, Graux C, Van Roosbroeck K, Ferrando AA, Langerak AW, Meijerink JP, Sigaux F, Haferlach T, Wlodarska I, Vandenberghe P, Soulier J, Cools J (2010) Deletion of the protein tyrosine phosphatase gene PTPN2 in T-cell acute lymphoblastic leukemia. Nat Genet 42:530-535

Kleppe M, Tousseyn T, Geissinger E, Kalender Atak Z, Aerts S, Rosenwald A, Wlodarska I, Cools J (2011) Mutation analysis of the tyrosine phosphatase PTPN2 in Hodgkin's lymphoma and T-cell non-Hodgkin's lymphoma. Haematologica 96:1723-1727

Lam MH, Michell BJ, Fodero-Tavoletti MT, Kemp BE, Tonks NK, Tiganis T (2001) Cellular stress regulates the nucleocytoplasmic distribution of the protein-tyrosine phosphatase TCPTP. J Biol Chem 276:37700-37707

Lee CF, Ling ZQ, Zhao T, Fang SH, Chang WC, Lee SC, Lee KR (2009) Genomic-wide analysis of lymphatic metastasis-associated genes in human hepatocellular carcinoma. World J Gastroenterol 15:356-365

Lee H, Kim M, Baek M, Morales LD, Jang IS, Slaga TJ, Digiovanni J, Kim DJ (2017) Targeted disruption of TC-PTP in the proliferative compartment augments STAT3 and AKT signaling and skin tumor development. Sci Rep 7:45077

Omerovic J, Clague MJ, Prior IA (2010) Phosphatome profiling reveals PTPN2, PTPRJ and PTEN as potent negative regulators of PKB/ Akt activation in Ras-mutated cancer cells. Biochem J 426:65-72

Rutqvist LE, Johansson H (2006) Long-term follow-up of the Stockholm randomized trials of postoperative radiation therapy versus adjuvant chemotherapy among 'high risk' pre- and postmenopausal breast cancer patients. Acta Oncol 45:517-527

Sangwan V, Paliouras GN, Abella JV, Dube N, Monast A, Tremblay ML, Park M (2008) Regulation of the Met receptor-tyrosine kinase by the protein-tyrosine phosphatase $1 \mathrm{~B}$ and T-cell phosphatase. J Biol Chem 283:34374-34383

Shields BJ, Wiede F, Gurzov EN, Wee K, Hauser C, Zhu HJ, Molloy TJ, O'Toole SA, Daly RJ, Sutherland RL, Mitchell CA, Mclean CA, Tiganis T (2013) TCPTP regulates SFK and STAT3 signaling and is lost in triple-negative breast cancers. Mol Cell Biol 33:557-570

Ten Hoeve J, De Jesus Ibarra-Sanchez M, Fu Y, Zhu W, Tremblay M, David M, Shuai K (2002) Identification of a nuclear Stat1 protein tyrosine phosphatase. Mol Cell Biol 22:5662-5668

Tiganis T, Bennett AM, Ravichandran KS, Tonks NK (1998) Epidermal growth factor receptor and the adaptor protein p52Shc are specific substrates of T-cell protein tyrosine phosphatase. Mol Cell Biol 18:1622-1634

Tiganis T, Kemp BE, Tonks NK (1999) The protein-tyrosine phosphatase TCPTP regulates epidermal growth factor receptor-mediated and phosphatidylinositol 3-kinase-dependent signaling. J Biol Chem 274:27768-27775

Veenstra C, Perez-Tenorio G, Stelling A, Karlsson E, Mirwani SM, Nordenskoljd B, Fornander T, Stal O (2016) Met and its ligand HGF are associated with clinical outcome in breast cancer. Oncotarget 7:37145-37159

Yamamoto T, Sekine Y, Kashima K, Kubota A, Sato N, Aoki N, Matsuda T (2002) The nuclear isoform of protein-tyrosine phosphatase TC-PTP regulates interleukin-6-mediated signaling pathway through STAT3 dephosphorylation. Biochem Biophys Res Commun 297:811-817

Publisher's Note Springer Nature remains neutral with regard to jurisdictional claims in published maps and institutional affiliations. 